\title{
THE EMPLOYMENT OF DENTAL NURSES
}

\author{
David M. Roder, BDS, MPH*
}

\section{Introduction}

The term "(school) dental nurse" has come to refer to auxiliaries who cut and restore cavities in child ren's teeth after a training period of about two years. ${ }^{26.35 .5 \times .79}$ The nurses' responsibilities vary with the country, but invariably they inject local anesthetics; prepare cavities and place restorative materials; and extract primary teeth and, in some instances, permanent teeth. ${ }^{27.34 .5 \times .74}$ The preparation of cavities and extraction of teeth are among features which distinguish dental nurses from "expanded-duty dental auxiliaries," who merely restore cavities prepared by dentists. "0.26.42

Perhaps no dental personnel have faced more opposition from dentists than dental nurses. ${ }^{20,23.44 .54 .81}$ Even in New Zealand, where nurses were introduced in 1921 with support from the New Zealand Dental Association, initial opposition from sectors of the profession was obvious. ${ }^{18.33}$ Possibly the strongest resistance has been expressed in the United States. In 1949, the Massachusetts Legislature approved a five-year experiment with dental nurses, but after little more than a year, the enabling legislation was repealed following opposition from organized dentistry. ${ }^{23}$ The American Dental Association proclaimed in 1949 that programs to teach people to treat child ren's teeth should not be less rigorous and time-consuming than for dentists. ${ }^{7}$ The Association called for a study into the effects of all programs employing dental nurses, wherever they might be established. ${ }^{4}$ Since then, the Association has been steadfast in opposing the preparation of cavities in teeth by auxiliaries. ${ }^{9}$

Nonetheless, approximatley 30 countries use dental nurses. ${ }^{24.35 .58}$ In this review, factors that should be considered when deciding whether to introduce dental nurses are discussed, together with pertinent literature. Although data exist on the dental nurses' productivity and quality of restorative care, other aspects such as effects on dentists' job satisfaction or on the public's access to care have not been evaluated statistically and are open to conjecture.

\section{Countries Employing Dental Nurses}

Dental nurses have been reported in Australia, Brunei, Burma, Canada, Ceylon, Columbia, Costa Rica, Cuba, Ghana, Haiti, Hong Kong, Indonesia, Italy, Jamaica, Kenya, New Zealand, Nigeria, Papua New Guinea, Paraguay, Senegal, Sierre Leone, Sudan, Singapore, South Vietnam, Taiwan, Thailand, Uganda, the United Kingdom, and Zambia. ${ }^{26.35 .58}$

New Zealand commenced a dental nurse program in 1921, but about 30 years elapsed before similar programs began to develop elsewhere. ${ }^{58}$ Malaysia initiated a scheme in 1949, followed by Indonesia (1953), Ceylon (1955), and Papua New Guinea (1956). ${ }^{58}$ Approximately 40 years followed the initial New Zealand experience before dental nurses were introduced to other societies where dental professions and dental services were highly advanced and organized. The United Kingdom commenced an experimental dental nurse program in 1960 , and continued the program after termina-

\footnotetext{
*Visiting Assistant Professor Program in Dental Public Health School of Public Health, The University of Michigan, Ann Arbor, Michigan 48109 (Dr. Roder may be addressed at: 103 Cheltenham St., Malvern 5603, South Australia.)
}

(Submitted 10/27/77; returned for revisions $11 / 18 / 77$; resubmitted $11 / 28 / 77$; accepted $2 / 28 / 78$.) 
tion of the experimental phase in 1966. ${ }^{34.5 x}$ Further programs began in the Australian states of Tasmania (1966) and South Australia (1967), and in the Canadian province of Saskatchewan (1972). ${ }^{35.5 \% .74}$ Also in 1972, a small experimental program to teach hygienists to inject local anesthetics, prepare cavities, and place restorations was started at the Forsyth Dental Center in Massachusetts. ${ }^{49}$ However, this program was terminated in 1974 for noncompliance with the State's dental act. ${ }^{48}$ The validity of some of the research findings were criticized by a commission of inquiry appointed by the Massachusetts Dental Society and funded in part by the American Dental Association.21

It is reasonable to infer from these developments that there is persistent support for the utilization of dental nurses around the world, despite opposition from some sectors of the dental profession -- particularly organized dentistry in the U.S.

\section{Introduction of Dental Nurses - Relevant Considerations}

Availability of Dental Manpower. The arguments in favor of employing dental nurses may be more compelling when there is a shortage of dentists. A British governmental commission once stated that when there is a manpower shortage in a professional field, it is a well-established practice to assign simpler duties to auxiliaries, thereby reducing the burden on the fully trained professional. ${ }^{42}$ There is evidence that this rationale has been persuasive in the introduction of dental nurses.

Ast ${ }^{10}$ reported that dental nurses were originated because of insufficient dental manpower in New Zealand. It has been speculated that dental practitioners possibly provided litle care for children at that time, and therefore did not perceive the dental nurse scheme as a great threat to their livelihood. ${ }^{18}$ The need for increased dental manpower was highlighted by bad dental health in children and in troops during World War I. ${ }^{10.15 .11}$

In 1949, Malaysia became the first of several developing nations to introduce dental nurses. ${ }^{58}$ This intervention also was attributed to an acute shortage of dental manpower. ${ }^{18}$

"New Cross dental auxiliaries" (dental nurses) initially were trained in the United Kingdom in 1960. ${ }^{34.58}$ The Priority Dental Services Sub-Committee of the British Dental Association had indicated the need for more school dental manpower, and it seemed that the introduction of dental nurses would help meet this need. ${ }^{17}$ Similarly in Australia and Saskatchewan, a shortage of dentists and an intent by government to extend school dental services led to the training and employment of dental nurses. ${ }^{3.61} 74$

Although not related directly to dental nurses, recent developments in the United States indicate the extent to which dental manpower availability can affect decisions on the use of auxiliaries. As early as 1961, the American Dental Association had advocated experimentation with "expanded-duty dental auxiliaries" when it seemed that a shortage of dentists was imminent. ${ }^{8.45}$ After investigations demonstrated that auxiliaries could place high-quality restorations with economic advantages, $1.2 .13 .14 .16 .39 .41 .43 .51-5.53$. $62-64.67 .64 .76$ the Association resolved that auxiliaries should not perform this procedure. ${ }^{9}$ The change in policy coincided with an increased availability of dentists, ${ }^{5.619 .85}$ a sharply reduced birth rate, ${ }^{83}$ and an economic recession, which could have reduced the public's demand for care per dentist. ${ }^{29}$

From this review, one may conclude that dental manpower shortages most likely were a major determinative factor in the introduction of dental nurses around the world. 
Cost of Care. Although it is understandable that a shortage of dentists could lead to training of more dentists, it is not clear why dental nurses have been trained, rather than just more dentists. There seems to be an assumption, with supporting evidence, that nurses would be more economical. 22.41 .56 .73

Dunning ${ }^{22}$ quoted New Zealand data on direct costs of two government-financed dental programs for schoolchildren. In the first, salaried dental nurses treated children under 14 years of age, whereas the second program reimbursed dentists on a fee-forservice basis to treat teenagers. Dunning noted that the annual cost per patient was almost 50 percent lower in the dental nurse system, even though the numbers of restorations and complete cycles of care seemed comparable. Since training costs of dentists and nurses, years of working life, rent and insurance in the dental nurse program, types of restorations, and numbers and types of other treatments were not taken into account; it was indicative but not conclusive that nurses were less expensive. It has been contended that fee-for-service systems are less efficient than salaried systems; ${ }^{30}$ if so, the argument in favor of dental nurses is strengthened. In other words, nurses might have seemed more economically advantageous in New Zealand, had they been reimbursed in the same manner as dentists. Dunning's observations on costs were confirmed by Redig, Dewhirst, Nevitt, and Snyder in a later visit to New Zealand. ${ }^{66}$

Roder ${ }^{73}$ has calculated from South Australian data that dental nurses would be more economical than dentists. Only direct costs to a government employing agency were considered. Because dentists were educated separately, their training costs were not included. Therefore, the calculation was weighted against the nurses. Since statistical evaluation of restorative productivity indicated that nurses and dentists were comparable for the limited services considered, Roder made direct comparisons of salaries. One eighth of the direct costs of training nurses was included with their salaries, since the prevailing annual loss rate ( $12 \frac{1}{2}$ percent) was consistent with an eight-year span of working life. On this basis, the salary cost per operator for teams of one dentist and seven therapists was 25-30 percent lower than for dentists. When calculating the dentists' salaries, Roder assumed that their average working-life-span would be 30 years. He also contended that there was a division of labor between dentists and nurses in South Australia, with no duplication of effort.

Neither general information on costs nor productivity data was reviewed for the United Kingdom, but $\mathrm{McHugh}^{56}$ estimated that after adjusting for differences in working-life-span, employing dental nurses would cost the community about a third less than employing dentists. It does not follow automatically that the cost of care would be reduced; the relative productivity of dentists and dental nurses also should be considered.

Hankin, an economist, analyzed productivity data from the Massachusetts experiment, in which hygienists cut cavities and placed restorations. ${ }^{41} \mathrm{He}$ estimated that a team of one dentist and 10 hygienists would provide restorative care at a persurface supply price of $\$ 5.00$, which was lower than the fee for one-surface amalgam restorations for welfare patients $(\$ 7.00)$ or for New England in general $(\$ 9.00)$. Doubt could be cast on the appropriateness of these fees as comparative standards, unless the per-surface cost can be equated with the fee for one-surface restorations in New England, or alternatively, the care provided was converted to one-surface-restoration equivalents. As in the New Zealand example, costs were compared between systems that differed not only by employment of dental nurses but also by method of payment 
and other characteristics. Therefore, it is difficult to isolate the effect on cost differences of using dental nurses per se. Although factors affecting internal validity may be controlled effectively in small-scale experimental situations such as the Massachusetts project, external validity may be jeopardized by special features such as participants of unusual caliber.

Although inconclusive, collective findings suggest that dental nurses present cost savings. Their effect on costs largely would depend on the relative training costs and working-life spans of dentists and nurses, their relative incomes, the extent to which incomes of dentists increase as a result of supervising dental nurses, the relative productivity of dentists and nurses under normal circumstances, the extent to which dentists become nonproductive through supervising nurses, and the ratio of dental nurses to supervising dentists.

Scarrott ${ }^{78}$ claims that economic advantages of dental auxiliaries would depend to a large degree on the tasks delegated. Advantages would be possible to the extent that more frequently required tasks were delegated, thereby increasing the potential ratio of auxiliaries to dentists. Accordingly in New Zealand, where nurses diagnose and plan treatment for caries, it might be expected that nurses would effect greater economies than in the United Kingdom, where these generally required tasks are the dentists' responsibility. ${ }^{10.26 .42}$ Regarding an additional aspect, Scarrott ${ }^{78}$ claims that costs have been reduced by limiting the career of dental nursing to females who in turn have low salaries.

Quality of Care. Although dental nurses have existed for over 50 years, few careful statistical assessments have been directed at the clinical quality of the various aspects of their care, such as provision of local anesthetics, and preparation and restoration of cavities in teeth. Although "expanded-duty dental auxiliaries" have been evaluated extensively in experimental settings, ${ }^{50.51}$ frequently using assessments of quality of care provided by dentists as comparative standards; dental nurses mostly have been appraised on an empirical and impressionistic basis. ${ }^{11,36,57,60}$ Such statistical evaluation as has been carried out and published, now will be reviewed, and the employed quality standards identified.

Assessments of Restorative Care - 1950's. At the time of the initial Massachusetts experiment with dental nurses, the American Dental Association sent a staff member, Gruebbel to New Zealand to evaluate the dental nurses' care. ${ }^{38}$ The report, published in 1950, revealed that 3,220 restorations were inspected in the permanent teeth of 10-14 year olds in five geographic areas; 28 percent were considered "defective" either because of inadequate margins (11 percent), poor form (10 percent), or fractures of the restoration (five percent) or tooth (two percent). Assessments relied on empirical judgment without definitive criteria. A total of 61 bitewing radiographs was obtained for children selected at random from 121 10-14 year olds. Easlick reviewed the radiographs and concluded that they revealed a poor quality of care by U.S. dental school standards, but that radiographs of practicing dentists' care in the U.S. were not available for comparative purposes. Gruebbel's report would have been improved had the sampling method been defined, and comparative quality standards based on dentists' restorations been provided.

Fulton, assisted by a World Health Organization grant, visited New Zealand at about the same time as Gruebbel. ${ }^{33}$ As dental adviser to the Children's Bureau, Fulton had advocated the experiment with the dental nurses in Massachusetts. ${ }^{23}$ Fulton's 
report indicated that 4,072 7-14 year olds were examined through a "random selection" of schools located within 100 miles of the major cities of Auckland and Christchurch. ${ }^{33}$ To increase surveying efficiency, schools with fewer than 200 child ren were not surveyed. Fulton considered that it would have been too time consuming to survey a sample drawn from the entire country. Fulton's evaluation was directed more at discrepancies between "care needed" and "care received", than at quality of individual items of care; for example, the high $\mathrm{F}$ to $\mathrm{DMF}$ ratio, and low $\mathrm{M}$ and $\mathrm{D}$ scores were described. Nonetheless, the low $M$ scores and high DMF rates indicate that the quality of restorations was at least sufficient to prevent substantial tooth loss. A total of 38 bitewing radiographs was selected haphazardly; Fulton examined them and concluded that many teeth were restored and thereby retained. Some older child ren had been treated in both the dental nurse system and a government-financed, fee-forservice program utilizing private practitioners. Fulton noted empirically that 207 teeth had restorations of an exceptional quality; a subsequent check showed that 82 percent of them had been restored by nurses. The data suggest that dental nurses can provide high quality restorations, but the relative quality of dentists' and nurses' restorations could not be determined since the total numbers of restorations placed by the two types of operators were not specified. In other words, it was not possible to discern whether the proportion of restorations which were of an exceptional quality was greater for nurses or dentists. Even with this information, results could have been confounded by extraneous quality-related differences in the salaried (nurses) and fee-forservice (dentists) systems. Fulton also reported positive impressions gained while observing trainees provide care.

Assessments of Restorative Care - 1960's. Fifteen years elapsed before, in 1966, an additional statistical assessment of dental nurses' care was reported. ${ }^{3.3}$ The British General Dental Council appointed 28 "independent" dentists to assess the quality of restorations placed by "New Cross dental auxiliaries." These dent ists inspected 13,303 teeth restored by auxiliaries for 2,892 patients in various geographic locations. Attempts were made to obtain a representative sample, but administrative complexities precluded an ideal random approach. The method of selecting the 28 dentists was not detailed. The dentists were asked to examine each restoration's surface, outline, contour, and edges, and to note the presence of neighboring carious lesions, when empirically assessing quality. Collectively, 91 percent of nurses' restorations were rated as "satisfactory," which was interpreted as a favorable endorsement of the nurses' performance. Comparative standards based on the quality of dentists' restorations were not used.

Assessments - 1970's. Roder's evaluation of the South Australian dental nurse program has been directed more at overall public health aspects, rather than quality of individual items of clinical care. ${ }^{71.72}$ Nevertheless, inferences of quality of nurses' restorative care can be drawn. The dental nurse program included only primary schoolchildren (ages five-12 years). Roder surveyed secondary school students who had ceased to be eligible for care from nurses about 18 months beforehand. Students were drawn from the major secondary schools located near each primary school that had a clinic for nurses. All subjects with a history of care in the dental nurse system were examined, along with a comparison group which never had been treated in that system and was selected at random from the same secondary schools. Of the 8,734 restored teeth in subjects who had been treated in the dental nurse system, 1.8 percent 
had a defective restoration, as opposed to 2.6 percent for teeth in child ren treated only by private dentists. To be "defective," an interior wall of a cavity had to be clinically visible. The results, though based on superficial criteria, suggest that nurses can perform an adequate quality of care. Nonetheless, several weaknesses in research design were apparent. The examiner attempted to examine subjects "blind," but individuals exposed to the dental nurse program usually could be identified by a characteristic outline and form of their restorations. Also, some of their restorations would have been placed by private dentists after students had left the dental nurse system; it was apparent that 40 percent of these students had visited a private dentist during that time period. As in previously reported studies, there may have been extraneous confounding factors associated with the salaried (nurses) and fee-for-service (dentists) systems; for example, differences in financial incentives, facilities and equipment, which might affect quality of care.

Following a proposal by Ingle, while Dean of the School of Dentistry, University of Southern California, that dental nurses be introduced, and the establishment of a committee by the governor of California to make recommendations to the legislature and State Board of Dental Examiners on the employment of dental auxiliaries; the California and Southern California Dental Associations sent an investigative team to New Zealand. ${ }^{66}$ The team consisted of two dental educators, Redig and Nevitt; a private dentist, Dewhirst; and a health statistician, Snyder. A total of 119 children aged five-14 years was examined in four areas of the country. The sample was not considered to be statistically ideal, but appeared to the investigators to be representative. Restorative quality was rated, using the method of Ryge and Snyder. ${ }^{77}$ Of the 33I copper-amalgam restorations inspected, 87.3 percent were considered "satisfactory," whereas the corresponding percentage was 97.1 for 477 silver-amalgam restorations. Immediate replacement was indicated for two copper amalgams and no silver amalgams. Conclusions generally were critical of the appropriateness of the New Zealand dental nurse system to California, particularly in view of the reported obsolescence of equipment, extensive standardization in the training of dental nurses, and lack of scope for continuing education. Dunning ${ }^{24}$ criticized these conclusions, stating that data did not demonstrate poor restorative quality, restorations placed by dentists were not examined for comparative purposes, and that features of the New Zealand system that were criticized were of secondary importance and need not be repeated in other dental nurse programs.

In another investigation, three dental educators, Ambrose, Hord, and Simpson, evaluated restorations provided by Saskatchewan dental nurses. ${ }^{3}$ Classrooms were sampled by an undescribed technic, and 410 children were inspected at 16 school clinics in five of the province's six health regions. A total of 300 children was enrolled in the dental nurse system and presented restorations provided both by nurses and dentists. The other 110 children had been treated by dentists only. Children were examined "blind" and 2,204 restorations assessed by rating the quality of features such as marginal adaptation and anatomical form on a scale from one to three. The restoration's score was the mean of scores for the separate features. After examinations, records were checked to identify those restorations placed by dentists and those by nurses. The quality of amalgam restorations placed by nurses was found to be better than those of the dentists, but stainless steel crowns placed by nurses and dentists were comparable in quality. It should not be concluded that nurses were more competent 
than dentists at placing amalgam restorations. Potentially confounding variables included differential effects of the salaried (nurses) and fee-for-service (dentists) systems. Also, the investigators questioned whether quality of the nurses' care might not have been enhanced by a Hawthorne effect, resulting from pioneering aspects of the new program.

The final report of the Massachusetts experimental project recounts that three formal "blind" evaluations of restorative quality were undertaken by "extramural" examiners. ${ }^{48}$ In the first two evaluations, examiners were members of the Massachusetts Dental Society's Forsyth Special Liaison Committee. For the third evaluation, examiners were provided by dental faculties at Tufts, Harvard, and Boston University Schools of Dental Medicine. The numbers of examiners ranged from two to six. Features of cavity preparations and recently placed restorations were rated from one to four, depending on their physical qualities. Control restorations were provided by the project's staff dentists. It was concluded from data obtained through these "blind" examinations that hygienist-nurses performed restorative dental care equal in quality to that provided by practicing dentists. The commission appointed by the Massachusetts Dental Society ${ }^{21}$ was critical of several aspects of the study, including the small number of hygienist-nurses' restorations (62) that were appraised by "extramural" examiners, that these restorations were not selected according to the usual definition of true random sampling, and that evaluations were undertaken when the restorations were placed, and so any defects appearing at a later time would not have been recorded. Nonetheless, the commission acknowledged that findings on restorative aspects were consistent with other studies.

Assessments of Nonrestorative Care. Virtually no statistical evaluation of quality has been accomplished for frequently required nonrestorative tasks. It is apparent from the report of the Massachusetts experimental project that hygienist-nurses administered approximately 17,000 local anesthesias by either infiltration or mandibular-block technics; 92 percent were considered by project staff to be successful. ${ }^{48}$ During the phase of clinical practice, the intervention of a dentist was considered necessary for acceptable anesthesia in only about one percent of administrations. No serious effects on health were apparent. Comparative standards based on the performance of dentists were not available.

Ambrose, Hord, and Simpson ${ }^{3}$ assessed the quality of radiographs exposed by Saskatchewan dental nurses as "generally good," but the investigators reported that no direct comparison of quality could be made with films exposed by dentists. ${ }^{3}$

There is a need for additional evaluation of the provision of local anesthesia and exposure of radiographs. The charting of carious lesions warrants special attention, since this task is required universally in children and often is withheld from dental nurses. ${ }^{10.25 .42 .59} \operatorname{Roder}^{70}$ evaluated the performance of South Australian dental nurses at diagnosis and treatment planning for carious lesions. A total of 470 child ren was selected at random from those due for an examination in the dental nurse system. Each child was examined independently (with treatment planning) by a dental nurse, a dentist who supervises nurses, and a tutor dentist from the training school for dental nurses. All of the program's 47 dental nurses, 10 supervising dentists, and eight tutor dentists participated in the study. The number of teeth that would have been treated differently by the nurses and supervising dentists was no greater than between the supervising and tutor dentists. Roder concluded, therefore, that nurses probably were 
competent at this task. Since nurses would not have referred about 23 percent of children whom their supervising dentists claimed were in need of a dentist's attention, dentists continue to maintain a "periodic surveillance" of each child.

These evaluations of quality of care are important, because the competence of nurses should be considered when contemplating their introduction to a dental system. Statistical evaluation of performance is incomplete, but there is support for claims that dental nurses can recognize and plan treatment for carious lesions, and restore teeth with amalgam materials.

Access to Care. If day-to-day supervision of dental nurses by dentists is not required, and if nurses are responsible for diagnosing and planning treatment for carious lesions; they may be deployed in sparsely populated areas at some distance from dentists, thereby increasing the public's access to care. ${ }^{78}$ New Zealand, Saskatchewan, and Australian nurses have been so deployed. ${ }^{3.27 .74}$

In the United Kingdom, all diagnosis and treatment planning is the dentists' direct responsibility. ${ }^{34}$ Also, dental nurses may not provide mandibular-block anesthesia. ${ }^{34}$ Therefore, nurses must work near dentists. The need to group dental personnel might not seriously reduce access to care in large cities like London, but this problem might follow in rural areas. ${ }^{34,68,78}$

Consequently, dental nurses may be contraindicated in sparsely populated regions, if for reasons of quality or control, it was considered necessary for them to work in close proximity to dentists.

Control of Nurses. When dental nurses are advocated, it is natural that some dentists would wonder whether future career encroachment by nurses might reduce the dentists' control of dentistry. ${ }^{28,65.66 .79 .80}$ In that event, what would be the effect on dentists' economic well-being and on quality of care?

Until now, there have been no reports of nurses extending their scope of work through career aggressiveness. Dental nurses as a group have been controlled by several means. For example, tasks that may be performed by nurses, where nurses may be employed, their supervision by dentists, and the population groups that they may treat often are defined in legislation. ${ }^{37.46,47}$

Additional methods of control are apparent, although less obvious and open to speculation. For example, by excluding frequently required procedures such as diagnosis and treatment planning from the nurses' scope of care, the nurses' potential numerical strength and independence from dentists may be reduced. These duties might be withheld primarily for other reasons, but any effect on control would still be the same. In addition, it might be necessary that the range of care left for the dent ist be broad and varied, if dentists are to retain sufficient job satisifaction to remain in a program and provide the professional oversight that is planned.

It has been traditional for dental nurses to be female. ${ }^{22.25}$ It has been contended that this development may have facilitated control; Dunning ${ }^{22}$ considers that females have showed less career ambition than males. With a working-life of about 10 years only, ${ }^{22}$ the time available to express career ambition has been limited. Today, social change is leading females to pursue careers and equality with males in careers, and males are becoming dental nurses. ${ }^{12}$ Therefore any control from restricting dental nursing to females may be diminishing.

Dental nurses generally have been limited to government services. ${ }^{10.15 .22 .25 .26 .82}$ The primary reason may have been a need to increase governmental dental manpower. 
However, it could be argued that nurses might be regulated more effectively in a highly organized environment. Control might be facilitated where one single administrative authority is directly responsible and accountable for the employment of nurses. Conversely, a certain number of dentists may feel threatened if governments were to train and employ their own special category of operator. There may be educators in university dental schools who resent the establishment of governmental training schools that are beyond their sphere of direct control. Consequently, the dental nurse might be regarded by some dentists as the government's auxiliary, with resulting apprehension and antagonism - depending on perceptions of government.

It has been reported that dental nurses in some programs have been trained to accept and conform with organizational standards, rather than to question and experiment. ${ }^{32.66}$ This may have enhanced control. Also it could be argued that control has been facilitated by not including nurses in positions of authority, such as on boards that administer dental legislation.

Dental nurses generally have been limited to the treatment of children. ${ }^{35}$ The reason may relate to the special needs of this population group, but certainly this restriction could limit the potential numerical strength of nurses.

It seems that "control" would be a central consideration, when dentists contemplate the introduction of dental nurses. Dentists would be concerned that their control of dentistry be safeguarded. No research studies on administrative control were reviewed; this aspect of employment is important and should be investigated for all types of dental personnel.

Flexibility of Technology. Several investigators have criticized what they consider to be outmoded aspects of the New Zealand dental nurse system. ${ }^{3 \times . h n}$ It is debatable whether technological obsolescence is associated with the employment of nurses. It may be theorized, however, that nurses would not be as aware as dentists of technical innovations, and therefore might be less likely to press for modernization. Even if they had this awareness, nurses may not carry the authority to achieve change.

When administrators decide that change is required, difficulties in implementation might be present, if there were too few dentists. For example, it might be difficult to introduce a new injection technic unless there are dentists available to teach the nurses. In other words, outmoded methods may be retained in the absence of sufficient dentists.

Other Considerations. When pressure is placed on governments to provide more dental manpower, dental nurses might be an attractive option because of the short duration of their training and the speed at which they can be introduced to the community. ${ }^{56}$

Individuals advocating the employment of dental nurses have claimed that dentists' job satisfaction and status would be enhanced by delegating simple repetitive tasks, thereby releasing dentists to practice more advanced procedures. ${ }^{55}$ This argument may not appeal to those dentists who feel threatened by a role change, or are concerned that too few dental services would be left for them between the spheres of care of specialists and nurses.

Another argument favors the introduction of dental nurses because, it is perceived, reductions in "social distance" between dental providers and patients would result. ${ }^{31}$ This argument may be valid, but no scientific evidence on this subject was reviewed. 
Opponents of dental nurses sometimes draw attention to the high prevalence of edentulousness in New Zealand. ${ }^{28}$ There is no evidence, however, that edentulousness follows from the employment of dental nurses. The prevalence of edentulousness is high in many countries without a history of employing nurses. ${ }^{75,44}$

It has been claimed that dental nurses should be trained where manpower needs are uncertain so that in the event of training too many personnel, the waste of training resources would be less than for dentists. ${ }^{75 . \times 4}$ Alternatively, it could be argued that the training of generalists (dentists) would be preferable, since they would be more versatile and could more easily redirect the emphasis of care, should treatment needs change.

Unlike "expanded-duty dental auxiliaries," dental nurses can provide complete units of restorative care and can work more independently of a dentist. This independence may simplify the scheduling of patients to keep both the auxiliary and dentist occupied. ${ }^{62}$ Also, the dentist would be freed from cavity preparations for the nurse's patients, and thereby be able to practice other types of care.

\section{Summary}

Dental nurses who prepare cavities in teeth have faced considerable opposition from sectors of the dental profession, even where policies of dental associations have supported their employment. Nonetheless, approximately 30 countries utilize these personnel. In New Zealand 50 years after the introduction of dental nurses, it is apparent that these auxiliaries are fully accepted by the dental profession. ${ }^{32}$

A major factor predisposing to the introduction of dental nurses is a shortage of dental manpower. Such statistical data as are a vailable indicate that dental nurses can provide restorative care of an acceptable standard more economically than dentists. Decisions on whether dental nurses should be employed also would be influenced by less tangible considerations, such as the fear expressed by some dentists that the profession's control of dentistry may be reduced.

Where dental nurses have not been required to work in close proximity to dentists, they have increased the public's access to care. Nurses who are required to work near dentists may be contraindicated in sparsely populated regions; in these places, dentists might be preferable since they may work alone and be dispersed to facilitate access to care.

Control of the dental nurses' scope of services has been undertaken through legislation. It may be speculated that several features of the employment of nurses have been conducive to the administrative control of these auxiliaries, although not necessarily introduced for that purpose; for example, limiting the range of tasks that they may perform, engaging only females, restricting their care to children and their employment to government.

\section{References}

1. Abramowitz, Joseph. Expanded functions for dental assistants: a preliminary study. Am. Dent. A. J., 72:386-91. Feb. 1966.

2. Abramowitz, Joseph, and Berg, L. E. A four-year study of the utilization of dental assistants with expanded function. Am. Dent. A. J., 87:623-35, Sept. 1973

3. Ambrose, E. R., Hord, A. B., and Simpson, W. J. A quality evaluation of specific dental services provided by the Saskatchewan Dental Plan: final report. Regina, Commercial Printers, Feb. 1976. 19 p.

4. American Dental Association, Board of Trustees. Dental nurses. Am. Dent. A. Tr., 90:340-1, 1949.

5. American Dental Association. Bureau of Economic Research and Statistics. Growth in population and number of dentists to 1985. Am. Dent. A. J., 87:901-3, Oct. 1973. 
6. - Number of dental graduates required annually to 1985. Am. Dent. A. J., 71:694-8, Sept. 1965.

7. American Dental Association, House of Delegates. Dental nurses. Am. Dent. A. Tr.. 90:245. 1949.

8. _. Statement of policy regarding experimentation in training and utilization of dental hygienists and dental assistants. Am. Dent. A. Tr., 102:222-3, 1961.

9. Study and reevaluation of expanded functions for dental auxiliaries. Am. Dent. A. Tr. 116:697-703, 1975.

10. Ast, D. B. Oral health delivery systems: changes resulting from more efficient preventive measures and use of auxiliaries. p. 129-86. (In Brown, W. E., ed. Oral health, dentistry, and the American public; the need for an improved oral care delivery system. Norman, Okla., University Oklahoma Press. cl974. vii +372 p.)

11. Australian Dental Association, National dental health. Queensland Dent. J., 2:314-6, June-Oct. 1949.

12. Australian School Dental Service. FDI Newsletter, No. 90. Apr. 1975. 36 p. (p. 33)

13. Baird, K. M., Covey, G. R., and Protheroe, D. H. Employment of auxiliary clinical personnel in the Royal Canadian Dental Corps. Canad. Dent. A. J., 33:184-91. Apr. 1967.

14. Baird, K. M., Purdy, E. C., and Protheroe, D. H. Pilot study on advanced training and employment of auxiliary dental personnel in the Royal Canadian Dental Corps: final report. Canad. Dent. A. J., 29:778-87, Dec. 1963.

15. Berman, D. S. Utilization of the dental auxiliary-school dental nurse. Internat. Dent. J., 19:24-40, Mar. 1969.

16. Brearley, L. J., and Rosenblum, F. N. Two year evaluation of auxiliaries trained in expanded duties. Am. Dent. A. J., 84:600-10, Mar. 1972.

17. British Dental Association, Priority Dental Services Sub-Committee. Memorandum on the Local Authority Dental Services. Brit. Dent. J., 109:275-85, Oct. 4, 1960.

18. Burt, B. A. The administration of public dental treatment programmes. p. 113-33. (1n Slack. G. L.., and Burt. B. A., eds. Dental public health; an introduction to community dentistry. Bristol. Wright, 1974. $\mathrm{ix}+338$ p.)

19. Butts, H. C. Dental manpower shortage? Edit. Am. Dent. A. J., 93: 507, Sept. 1976.

20. Dental auxiliaries cultural shock. Edit. Canad. Dent. A. J., 40:253, Apr. 1974.

21. Doerr, R. E., et al. The report of the commission to evaluate the "Final report: a study of new duties for dental hygienists" conducted at Forsyth Dental Center in Boston, Massachusetts. Mass. Dent. Soc. J., 25:201-16. Fall 1976.

22. Dunning. J. M. Deployment and control of dental auxiliaries in New Zealand and Australia. Am. Dent. A. J., 85:618-26, Sept. 1972.

23. _ Extending the field for dental auxiliary personnel in the United States. Am, J. Pub. Health, 48:1059-64, Aug. 1958.

24. __ New Zealand summary. Am. Dent. A. J., 88:271-3, Feb. 1974.

25. Principles of dental public health. Cambridge, University Harvard Press, 1970. xiv $+598 \mathrm{p}$. (p. 404-20)

26. Elderton, R. J. Dental ancillaries. p. 202-20. (In Slack, G. L., and Burt, B. A., eds. Dental public health; an introduction to community dentistry. Bristol, Wright, 1974. ix +338 p.)

27. Espie, J. G. New Zealand's dental service for children. Child.. 16:72-5, Mar.-Apr. 1969.

28. Fastabend, H. L. Let's proceed with caution on expansion. Calif. Dent. A. J., 1:30-2, Oct. 1973.

29. Feldstein, P. J. Financing dental care: an economic analysis. Lexington, Massachusetts, Heath, c1973. xvii +259 p. (p. 28-9).

30. Fisher, M. A. The costs of delivering dental services. J. Pub. Health Dent., 30: 76-9, Spring 1970.

31. Frazier, P. Jean. Consumer needs and perceptions: developing new types of dental auxiliaries. Am. Dent. Hyg. A. J., 48:37-45, Jan.-Feb., 1974.

32. Friedman, J. W. The New Zealand School Dental Service: lesson in radical conservatism. Am. Dent. A. J., 85:609-17, Sept. 1972.

33. Fulton, J. T. Experiment in dental care; results of New Zealand's use of school dental nurses. Geneva, World Health Organization, 1951.87 p.

34. General Dental Council. Final report on the experimental scheme for the training and employment of dental auxiliaries. London, Spottiswoode, Ballantyne, 1966. $100 \mathrm{p}$.

35. Gladstone, R. N. International dental nurse programs. Am. Dent. Hyg. A. J., 49:169-73. Apr. 1975.

36. Gonzalez, J. M. The New Zealand dental nurse; "Forty Four Years of Service." San Juan. Puerto Rico. Oral Health Division. Department of Health, Nov. 1967. 58 p. mimeog.

37. Governor of the State of South Australia. Dentists Act, 1931-1966. Adelaide, Government Printer, Oct. 26, 1970. 25 p. (p. 12-13)

38. Gruebbel, A. O. A study of dental public health services in New Zealand. Chicago, American Dental Association, $1950.59 \mathrm{p}$.

39. Hammons, P. E., and Jamison, H. C. Expanded functions for dental auxiliaries. Am. Dent. A. J.. 75:658-72, Sept. 1967. 
40. Hammons, P. E., Jamison, H. C., and Wilson, L. L. Quality of service provided by dental therapists in an experimental program at the University of Alabama. Am. Dent. A. J., 82:1060-6, May 1971.

41. Hankin, R. A. The cost of providing restorative dentistry in an alternative delivery mode. J. Pub. Health Dent., 37:217-23, Summer 1977.

42. Hobdell, M. H., Sheiham. Aubrey, and Allred, Harry. Dental auxiliaries (1): An annotated bibliography on the use of ancillary workers in dentistry. Quintessence Internat, 6:63-8, May 1975.

43. Hord, A. B., Thompson, G. W., and Ellis, R. L. The Ontario Dental Association demonstration project on dental auxiliaries with expanded duties: quality control study. Ont. Dent. A. J., 51:14-8, June 1974.

44. James, A. G. The invasion of dentistry. South Calif. S. Dent. A. J., 31:316-21, Oct. 1963.

45. Kesel, R. G. Dental research. p. 423-74. (In Hollinshead, B. S., dir. The survey of dentistry: the final report. Washington. American Council Education, c1961. xxxiv +603 p.)

46. I.egislative Assembly of Saskatchewan. An act respecting dental nurses. Regina, Queen's Printer, 1973. $8 \mathrm{p}$.

47. Legislative Assembly of Saskatchewan. Saskatchewan Regulation 268/73; The Saskatchewan Dental Nurses Act. 1973 -.-Section 16. Regina, Queen's Printer, 1974. 2 p.

48. Lobene, R. R. A study of new duties for dental hygienists; Final report. Boston, Forsyth Dental Center, Sept. 30, 1975, iii + 116 p. typed.

49. Lobene. R. R., et al. The Forsyth experiment in training of advanced skill hygienists. Am. Dent. Hyg. A. J., 48:204-13, July-Aug. 1974.

50. Lotzkar, Stanley, Johnson, D. W., and Thompson, M. B. Experimental program in expanded functions for dental assistants: phase 1 base line and phase 2 training. Am. Dent. A. J., 82:101-22, Jan. I971.

51. Experimental program in expanded functions for dental assistants: Phase 3 experiment with dental teams. Am. Dent. A. J., 82:1067-81, May 1971.

52. Ludwick, W. E., Schnoebelen, E. O., and Knoedler, D. J. Greater utilization of dental technicians. I. Report of training. Great Lakes, Ill., U. S. Naval Training Center, Dental Research Facility, 1963. 9 p. + III. lithographed.

53. __ Greater utilization of dental technicians. II. Report of clinical tests. Great Lakes, III., U.S. Naval Iraining Center, Dental Research Facility, 1964. 42 p. lithographed.

54. Lux. Brian. Auxiliaries - time to call a halt. Probe, 15:327-8, Jan. 1974.

55. McCalt, I. O. Dental practice and dental education in the future; with consideration of social and health aspects. Am. Dent. A. J., 31:16-30, Jan. 1944.

56. McHugh, W. D. Dentistry and the community. Brit. Dent. J., 121:428-31, Nov. 1, 1966.

57. Ministry of Health, Department of Health for Scotland, and Ministry of Education. New Zealand school dental nurses; report of United Kingdom Dental Mission. London, His Majesty's Stationery Office, 1950 . iv $+43 \mathrm{p}$.

58. Myers, Sharon E. Operating dental auxiliaries. J. Dent. Educ., 37:17-20, Feb. 1973.

59. National dental health policy. Austral. Dent. A. News Bul., June 1968.

60. New Zealand revisited. Edit. Canad. Dent. A. J., 31:592-3, Sept. 1965.

61. Norton, R. Y. Moves in dental health. Am. Dent. A. J., 87:9l-2, July 1973.

62. Obuhoff, O. N. Auxiliary utilization: increasing productivity and how to survive it. Calif. Dent. A. J., 2:28-36, Oct. 1974.

63. Pelton, W, J., Embry, O. H., Overstreet, G. A.. and Dilworth, J. B. Economic implications of adding two expanded-duty dental assistants to a practice. Am. Dent. A. J., 87:604-9, Sept. 1973.

64. Pelton, W. J.. Overstreet. G. A., Embry, O. H., and Dilworth, J. B. Economic implications of adding one therapist to a practice. Am. Dent. A. J., 86:1301-9. June 1973.

65. Professionalism. Edit. Austral. Dent. J., 19:359-60, Oct. 1974.

66. Redig, D. F., Dewhirst, Floyd, Nevitt, G. A., and Snyder, Mildred. Delivery of dental services in New Zealand and California. South Calif. Dent. A. J., 41:318-50, Apr. 1973.

67. Redig. D. F. Snyder, Mildred, Nevitt, G. A., and Tocehini, John. Expanded duty dental auxiliaries in four private dental offices: the first year's experience. Am. Dent. A. J., 88:969-84, May 1974.

68. Redwine, David, and Redwine, Debra. Expanded function auxiliary personnel. Am. Dent. Hyg. A. J., 48:81-6, Mar.-Apr. 1974.

69. Robinson, G. E., and Bradley, E. L. TEAM vs. DAU: a study of clinical productivity. Med. Care, 12:693-708, Aug. 1974.

70. Roder, D. M. Diagnosis, treatment planning and referral by school dental therapists. Austral. Dent. J., 19:242-9, Aug. 1974.

71. Dental Service. Austral. Dent. J., 18:311-9, Oct.-Dec. 1973.

72. T_ The effect of treatment provided by dentists and therapists in the South Australian School Dental Service. The second report. Austral. Dent. J., 21:147-52, A pr. 1976.

73. The planning and evaluation of a school dental programme. Adelaide, Government Printer, 1977. iii +455 p. typed thesis. (p. 307-16). 

1972.

The school dental therapist of South Australia. J. Pub. Health Dent., 32:70-82, Spring

75. Roder, D. M., and Selge. Bill. Tooth loss, the wearing of dentures and the demand for dental care in the south-east of South Australia. Austral. Dent. J., 19:399-407, Dec. 1974.

76. Romcke, R. G., and Lewis, D. W. Use of expanded function dental hygienists in the Prince Edward Island dental manpower study. Canad. Dent. A. J., 39:247-62, Apr. 1973.

77. Ryge, Gunnar, and Snyder, Mildred. Evaluating the clinical quality of restorations. Am. Dent. A. J.. 87:369-77, Aug. 1973

78. Scarrott, Diana M. The economic case for delegation in dentistry. Brit. Dent. J., 134:23-4, Jan. 2, 1973.

79. Scoles, Dixie C. The expanding roles of operating dental auxiliaries. Am. Dent. Hyg. A. J., 48:31-5, Jan.-Feb. 1974.

80. Slaughter, Freeman. Expanded-duty auxiliaries. Am. Acad. Gold Foil Operators J., 18:45-52, Fall 1975.

81. Soricelli, D. A. Implementation of the delivery of dental services of auxiliaries; the Philadelphia experience. Am. J. Pub. Health, 62:1077-87, Aug. 1972.

82. Striffler, D. F., and Gillespie, G. M. Dental manpower in the Americas and its implications for community programs of dental public health. Paper presented at the Hemispheric Conference, "Better Oral Health for the Americas," San Juan, Puerto Rico, Sept. 27-Oct. 1, 1965.

83. U. S. Bureau of the Census, Current Population Reports, Series P-25, No. 706. Estimates of the population of the United States and components of change: 1940 to 1976. Washington, U. S. Government Printing Office, Sept. 1977. 13 p.

84. U. S. Public Health Service, National Center for Health Statistics. Edentulous persons: United States1971, by Burnham, C. E. DHEW Publ. No. (HRA) 74-1516. Washington, U. S. Government Printing Office, 1974. iv. $+31 \mathrm{p}$.

85. Whiteside, D. F. Training the nation's health manpower - the next 4 years. Pub. Health Rep., 92:99107, Mar.-Apr. 1977

\title{
DIRECTOR OF COUNTY DENTAL PROGRAM
}

North Carolina - Greensboro - Director of County Dental Program - Academic, clinical \& administrative responsibilities - Maternal \& Child Health oriented - Program includes: Children \& Youth Project, School Health \& Preventive Program, and School of Dentistry Preceptorship. Annual Dentist budget $\$ 225,000$ - Salary \& academic appointment to the UNC School of Dentistry commensurate with qualifications - 4 years experience necessary - preventive program/administrative expertise desired. Reply to:

\author{
J. L. Holliday, M.D., MPH \\ Health Director \\ Guilford County Health Department \\ P. O. Box 3508 \\ Greensboro, N. C. 27401
}

